\title{
Use, Perspectives, and Attitudes Regarding Diabetes Management Mobile Apps Among Diabetes Patients and Diabetologists in China: National Web-Based Survey
}

Yiyu Zhang ${ }^{1,2,3^{*}}$, MMed; Xia Li ${ }^{1,2,3^{*}}$, MD; Shuoming Luo ${ }^{1,2,3}$, MD; Chaoyuan Liu ${ }^{4}$, MMed; Yuting Xie ${ }^{1,2,3}$, MD; Jia Guo $^{5}$, PhD, RN; Fang Liu ${ }^{1}$, MNurs, RN; Zhiguang Zhou ${ }^{1,2,3}$, MD

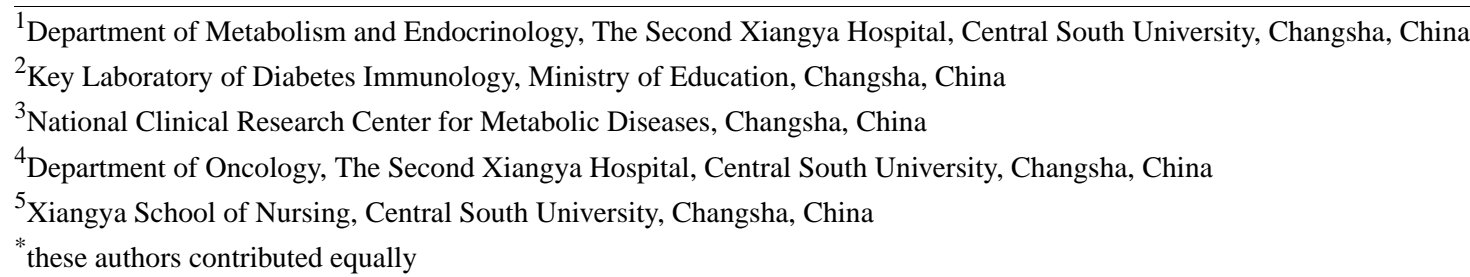

\section{Corresponding Author:}

Zhiguang Zhou, MD

Department of Metabolism and Endocrinology

The Second Xiangya Hospital

Central South University

No 139, Renmin Road

Changsha, 410011

China

Phone: 86073185292154

Fax: 86073185367220

Email: zhouzhiguang@csu.edu.cn

\section{Abstract}

Background: The diabetes disease burden in China is heavy, and mobile apps have a great potential for diabetes management. However, there is a lack of investigation of diabetes app use among Chinese diabetes patients and diabetologists. The perspectives and attitudes of diabetes patients and diabetologists regarding diabetes apps are also unclear.

Objective: Our objectives were to investigate diabetes patients' and diabetologists' use, attitudes, and perspectives, as well as patients' needs, with respect to diabetes apps to provide information regarding the optimal design of diabetes apps and the best strategies to promote their use.

Methods: Diabetes patients and diabetologists across China were surveyed on the WeChat (Tencent Corp) network using Sojump (Changsha ran Xing InfoTech Ltd) from January 23, 2018, to July 30, 2018. In total, 2 survey links were initially sent to doctors from 46 Latent Autoimmune Diabetes of Adults Study collaborative hospitals in China in 25 major cities and were spread on their WeChat contacts network. We also published the patient survey link on 3 WeChat public accounts and requested diabetes patients to fill out questionnaires. A multivariate regression analysis was used to identify associations of demographic and basic disease information with app usage among adult patients.

Results: Overall, 1276 individuals from 30 provincial regions responded to the patient survey; among them, the overall app awareness rate was $29.94 \%$ (382/1276) and usage was $15.44 \%(197 / 1276)$. The usage was higher among patients with type 1 diabetes (T1DM) than among patients with type 2 diabetes (T2DM; 108/473, 22.8\% vs 79/733, 10.8\%; $P<.001)$. The multivariate regression analysis showed that diabetes type, age, education, family income, and location were associated with app use in adult patients $(P<.05)$. The need for and selection of diabetes apps differed slightly between patients with T1DM and patients with T2DM. The reasons why patients discontinued the use of an app included limited time (59/197, 29.9\%), complicated operations (50/197, 25.4\%), ineffectiveness for glycemic control $(48 / 197,24.4 \%)$, and cost $(38 / 197,19.3 \%)$. Of the 608 responders to the diabetologist survey, $40.5 \%$ (246/608) recommended diabetes apps to patients and $25.2 \%(153 / 608)$ used diabetes apps to manage patients. The greatest obstacles to the diabetologists' use of apps to manage diabetes patients include limited time (280/608, $46.1 \%)$, legal issues $(129 / 608,21.2 \%)$, patients' distrust $(108 / 608,17.8 \%)$, and billing issues $(66 / 608,10.9 \%)$. 
Conclusions: The awareness and use of diabetes apps in Chinese people with diabetes and the proportion of diabetologists using diabetes apps to manage patients are low. Designing apps targeting different patient needs and conducting high-quality randomized controlled trials will improve the effectiveness of the apps, provide evidence for patients to choose suitable apps, and be conducive to the promotion of app use.

(JMIR Mhealth Uhealth 2019;7(2):e12658) doi: 10.2196/12658

\section{KEYWORDS}

diabetes mellitus; mobile applications; surveys and questionnaires

\section{Introduction}

\section{Background}

The prevalence of diabetes has been increasing worldwide. In 2017, it was estimated that there were 451 million people aged 18 to 99 years with diabetes. Furthermore, 5.0 million deaths were attributable to diabetes [1]. Among the Chinese adult population, the estimated prevalence of diabetes was $11.6 \%$, representing an estimated 113.9 million adults in China with diabetes. However, only $39.7 \%$ of those treated had adequate glycemic control [2]. Poor glycemic control can cause various complications [3] and bring heavy economic burden to the world. In 2015, the global cost of diabetes was estimated to be US $\$ 1.31$ trillion or $1.8 \%$ of the global gross domestic product (GDP) [4].

Diabetes self-management education and support (DSMES) is a critical element of care for patients with diabetes [5]. The AADE7 Self-Care Behaviors defined by the American Association of Diabetes Educators is a framework for patient-centered diabetes education and care [6]. The 7 self-care behaviors are eating healthy, being active, monitoring, taking medications, solving problems, healthy coping, and reducing risks, and these are essential for diabetes self-management. Due to an imbalance of medical resources in China [7], patients flock from rural areas to urban areas seeking medical resources. However, doctors in tertiary hospitals are overloaded with work $[8,9]$. Patients receive only a few minutes for outpatient consultation and receive little self-management knowledge in such a limited time. Furthermore, many outpatients do not have a record of their blood sugar; therefore, doctors cannot give accurate guidance for their treatment. Thus, a different type of health service might be needed to supplement traditional outpatient consultations.

Mobile apps can record, transmit, and receive feedback anytime and anywhere, facilitating remote monitoring and delivery of timely recommendations for health care. Mobile apps could increase the capacity for self-management, help sustain necessary lifestyle modifications, and improve communication between patients, family members, and health care professionals (HCPs). Furthermore, there were 1.32 billion mobile phone users in China in 2016 [10]. With the popularity of smart phones in China, mobile apps have great potential for managing chronic diseases, especially diabetes. A systematic investigation revealed that diabetes apps are the most common disease-specific apps in China's mobile health (mHealth) market [11]. Many studies have demonstrated that diabetes apps can potentially help control glycemia [12-16]. Mobile apps are also recommended by the American Diabetes Association guidelines for DSMES [17]. A meta-analysis of 21 randomized controlled trials (RCTs) showed that diabetes apps were associated with a mean reduction of $0.57 \%$ in glycosylated hemoglobin $\left(\mathrm{HbA}_{1 \mathrm{c}}\right)$ among patients with type 2 diabetes mellitus (T2DM) and $0.49 \%$ among patients with type 1 diabetes mellitus (T1DM). However, the results had significant heterogeneity [18]. Several studies also suggested that diabetes app use can increase blood glucose monitoring frequency $[13,19]$, reduce feelings of loneliness, help patients gain knowledge and skills to manage diabetes [20], improve hypoglycemic fears and behavioral scores [15], and strengthen the perception of self-care by offering better information and health education to patients [16].

Diabetes app usage varies among different countries [21-25], from $3 \%$ in Latin countries in 2015 [21] to $19.6 \%$ in New Zealand in 2016 [22]. China has the largest absolute disease burden of diabetes in the world and the greatest potential diabetes app market. However, there is a lack of large-scale investigations of the usage of diabetes apps in China. Patients' perspectives and attitudes regarding diabetes apps are also not very clear. In addition, user requirements are very important for app design. A survey by Boyle et al revealed that the most favored feature of patients was a glucose diary, and an insulin calculator was the most desirable function for a future app [22]. A survey by Trawley et al showed carbohydrate counting was the most common purpose among adults with T1DM and glucose monitoring was the most common purpose among adults with T2DM [23]. A recent meta-analysis of diabetes apps revealed that the reduction in $\mathrm{HbA}_{1 \mathrm{c}}$ is explained by the frequency of HCP feedback [18]. However, few surveys have been conducted to investigate the feature of patient-doctor communication. Our previous study found that both patients and diabetologists believed that doctor-patient communication and diabetes diaries were the most important functions of a diabetes app [26]. However, our previous study focused only on patients with T1DM and the samples were relatively small. Diabetologists' use, attitudes, and perspectives concerning diabetes management apps in China are poorly understood.

\section{Objectives}

The objective of our study was to investigate the use, perspectives, attitudes, and associated factors of diabetes patients and diabetologists regarding diabetes management apps, as well as patient needs for these apps, to provide information for the design of diabetes apps and how to best promote their use. 


\section{Methods}

\section{Questionnaire Design}

The questionnaire design was described in a previous study [26]. An expert panel consisting of 5 diabetologists (YZ, SL, $\mathrm{YX}, \mathrm{XL}$, and ZZ) and a diabetes education nurse (FL) searched apps from the iOS and Android platforms and designed the questionnaires according to the functions of current diabetes apps [25,27-31], diabetes guidelines [32], and the problems they encountered during clinical practice. The questions were presented in a choice format. If responders did not agree with the listed options, they could select the option others and write their answers in the remarks column. The diabetologist questions covered their basic information and use, attitudes, and perspectives regarding diabetes management apps. The patient questions covered their use, perspectives, and attitudes regarding and needs for diabetes apps, demographic information, and basic disease information.

To establish the validity of the content, the survey items were rated based on their relevance and clarity using a 4-point ordinal scale from 1 (irrelevant) to 4 (highly relevant) by 15 experts: 12 diabetologists and 3 diabetes education nurses with at least 5 years of experience treating patients with diabetes. The content validity indexes of the patient and diabetologist questionnaires were 0.91 and 0.93 , respectively. Before administering the questionnaires, we performed pilot tests with 20 patients with diabetes and 10 diabetologists from Second Xiangya Hospital. As 3 patients were unwilling to disclose their exact income and 1 doctor was reluctant to reveal his age, we revised our questionnaires such that patients were not required to answer the question regarding income and the doctors' ages were grouped into ranges. Cronbach alpha values for the patient and diabetologist questionnaires were .98 and .79 , respectively.

\section{Introduction of the WeChat Survey Platform}

WeChat provides many services, including messaging, free phone calls, browsing and posting for information sharing on moments, and mobile payments [33]. It is installed in over $90 \%$ of mobile phones and is integrated into most people's daily lives [34]. As the most widely and frequently used social communication tool in China, WeChat has a powerful contact network. As of 2016, over $44 \%$ of WeChat users had more than 200 contacts on the social networking service. Approximately $90 \%$ of WeChat users had more than 50 contacts [35]. This network makes it possible to administer questionnaires via WeChat.

\section{Samples and Survey Methods}

The participants were diabetes patients and diabetologists across China. Doctors at other departments who did not treat diabetes patients were excluded from our investigation.

Diabetes patients and diabetologists were surveyed through snowball sampling via the WeChat contacts network and convenience sampling through WeChat public accounts using the Web-based survey tool, Sojump, [36] from January 23, 2018, to July 30,2018 . The patient and diabetologist survey links were initially sent to doctors from 46 latent autoimmune diabetes of adults (LADA) Study China collaborative hospitals in 25 representative major cities in China [37]. We asked these doctors to spread the survey links on their WeChat contacts network. In addition to using snowball sampling through the WeChat contacts network, we published the patient survey link on 3 WeChat public accounts concerning diabetes, which have 50,000 subscribed followers, and asked diabetes patients to complete the questionnaires. The parents of juvenile patients answered the questions for their children. We introduced the background of our survey, and the questionnaires were completed voluntarily without any compensation. A part of the survey results concerning patients with T1DM has been reported in a previous study [26].

\section{Ethical Approval}

The study was approved by the ethics committee of the Second Xiangya Hospital, Central South University (ID: 2017-S107).

\section{Statistics}

The data were analyzed using SPSS version 23.0 (IBM Corp). Q-Q plots were used to check the normality of all the continuous variables, which are expressed as the means (SDs) or medians (interquartile ranges [IQRs]) where appropriate. Categorical variables are expressed as percentages (numbers, $n$ ). Differences among groups were assessed using Chi-square tests. The generalized logistic model was used to obtain odds ratios (OR) and their $95 \%$ CIs in a simultaneous manner. First, we performed a univariable analysis to obtain unadjusted ORs of potential correlates of app use with demographic factors and disease characteristics in adult patients (aged $\geq 18$ years). We then entered all the significant factors in the multivariate analysis to obtain the multivariable adjusted ORs. Questionnaires with missing values were excluded from the multivariate analysis. Statistical significance was indicated with $P<.05$.

\section{Results}

\section{Patient Survey}

\section{Sample Characteristics}

A total of 1276 patients with diabetes (414 from North China and 862 from South China) distributed among 30 provinces in China (Figure 1) responded to the patient survey. The responder characteristics are shown in Table 1. Of the responders, 50.31\% $(642 / 1276)$ were male, with a mean age of 41.3 years (SD 18.5). The mean disease duration was 6.8 years (SD 6.9). Overall, $37.07 \%$ (473/1276) were patients with T1DM and, of these, 178 were juveniles; $57.45 \%$ (733/1276) were patients with T2DM; $2.12 \%$ (27/1276) of the patients had gestational diabetes; and $3.45 \%$ (43/1276) did not know their diabetes type. 
Figure 1. Distribution of the diabetic patient sample in China by province.

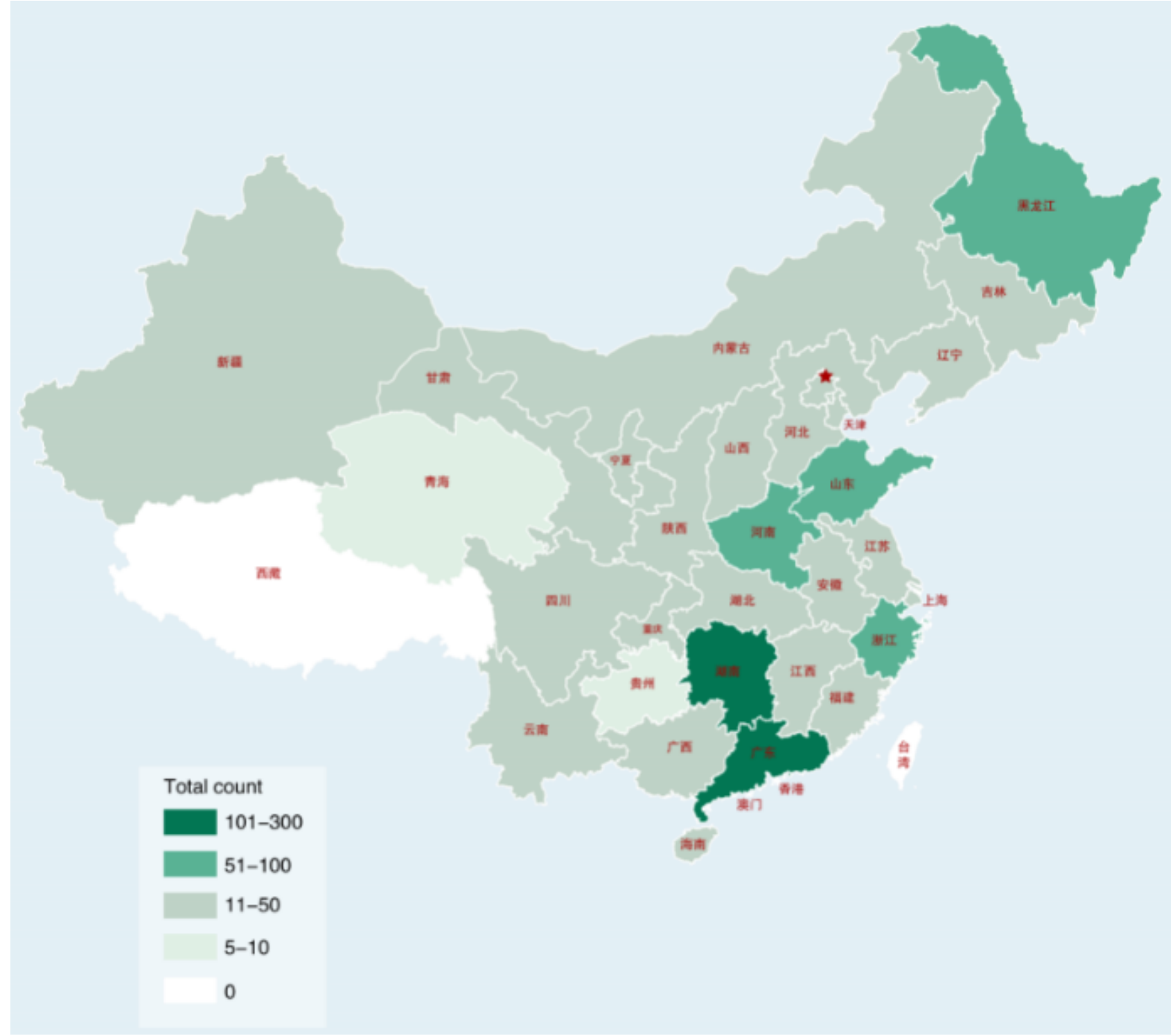


Table 1. Characteristics of patients with diabetes.

\begin{tabular}{|c|c|c|c|c|}
\hline \multirow[t]{2}{*}{ Characteristics } & \multicolumn{2}{|l|}{$\mathrm{T} \mathrm{DM}^{\mathrm{a}}(\mathrm{n}=473)$} & \multirow[t]{2}{*}{$\mathrm{T}_{2} \mathrm{DM}^{\mathrm{b}}(\mathrm{n}=733)$} & \multirow[t]{2}{*}{$\operatorname{Total}^{\mathrm{c}}(\mathrm{N}=1276)$} \\
\hline & Adults (n=295) & Juveniles $(n=178)$ & & \\
\hline \multicolumn{5}{|l|}{ Gender, n (\%) } \\
\hline Male & $115(39.0)$ & $81(45.5)$ & $426(58.1)$ & $642(50.31)$ \\
\hline Age (years), mean (SD) & $33.5(11.9)$ & $10.3(4.2)$ & $52.2(12.0)$ & $41.3(18.5)$ \\
\hline Disease duration (years), mean (SD) & $7.9(8.0)$ & $3.0(3.2)$ & $7.7(6.8)$ & $6.8(6.9)$ \\
\hline \multicolumn{5}{|l|}{ Residence, n (\%) } \\
\hline Urban & $206(69.8)$ & $110(61.8)$ & $572(78.0)$ & $933(73.12)$ \\
\hline Rural & $89(30.2)$ & $68(38.2)$ & $161(22.0)$ & $343(26.88)$ \\
\hline \multicolumn{5}{|l|}{ Education, $\mathbf{n}(\%)$} \\
\hline Junior middle school or below & $55(18.6)$ & ${ }_{-}^{\mathrm{d}}$ & $193(26.3)$ & $422(33.07)$ \\
\hline High school & $93(31.5)$ & - & $244(33.3)$ & $373(29.23)$ \\
\hline University or above & $147(49.8)$ & - & $296(40.4)$ & $481(37.70)$ \\
\hline \multicolumn{5}{|l|}{ Treatment, $\mathbf{n}(\%)$} \\
\hline Oral medicine & $14(4.7)$ & $1(0.6)$ & $379(51.7)$ & $416(32.60)$ \\
\hline Insulin injection & $196(66.4)$ & $128(71.9)$ & $281(38.3)$ & $636(49.84)$ \\
\hline Insulin pump & $83(28.1)$ & $49(27.5)$ & $9(1.2)$ & $144(11.29)$ \\
\hline Untreated & $2(0.7)$ & 0 & $64(8.7)$ & $80(6.27)$ \\
\hline \multicolumn{5}{|l|}{ Occupation, n (\%) } \\
\hline Student & $44(14.9)$ & - & $3(0.4)$ & $206(16.14)$ \\
\hline Institutional staff & $45(15.3)$ & - & $115(15.7)$ & $171(13.40)$ \\
\hline Employee of state-owned enterprise & $19(6.4)$ & - & $83(11.3)$ & $109(8.54)$ \\
\hline Employee of foreign or private company & $43(14.6)$ & - & $69(9.4)$ & $121(9.48)$ \\
\hline Private enterprise owner or self-employed & $26(8.8)$ & - & $77(10.5)$ & $113(8.86)$ \\
\hline Retired & $19(6.4)$ & - & $206(28.1)$ & $231(18.10)$ \\
\hline Farmer & $19(6.4)$ & - & $75(10.2)$ & $103(8.07)$ \\
\hline Unemployed & $47(15.9)$ & - & $70(9.5)$ & $131(10.27)$ \\
\hline Others & $33(11.2)$ & - & $35(4.8)$ & $9(7.05)$ \\
\hline
\end{tabular}

T1DM: type 1 diabetes mellitus.

${ }^{\mathrm{b}}$ T2DM: type 2 diabetes mellitus.

${ }^{\mathrm{c}}$ Total including patients with T1DM, patients with T2DM, 27 patients with gestational diabetes, and 43 patients with an unknown type of diabetes.

${ }^{\mathrm{d}}$ Indicates that there is no value.

\section{Diabetes App Use and Associated Factors Among Diabetes Patients}

The overall diabetes app awareness rate was $29.94 \%(382 / 1276)$, the usage rate was $15.44 \%(197 / 1276)$, and $43.7 \%(86 / 197)$ of the patients who use the apps used them every day. The app usage of patients with T1DM was higher than that of patients with T2DM (108/473, $22.8 \%$ vs $79 / 733,10.8 \%$; $P<.001)$. The utilization rate of adult patients with T1DM was higher than that of juvenile patients with T1DM $(80 / 295,27.1 \%$ vs $28 / 178$, $15.7 \% ; P=.004)$. A comparison of patients located in the 10 provinces of top GDP per capita [38] with the other 20 provinces showed that the former had higher diabetes app usage than the latter $(79 / 401,19.7 \%$ vs $118 / 875,13.5 \% ; P=.004)$.
The app usage of juvenile patients with T1DM treated with an insulin pump was higher than that of those treated with a subcutaneous injection $(13 / 49,26.5 \%$ vs $15 / 128,11.7 \%$; $P=.009$ ). The comparison of the 3 groups of juvenile patients with different parental educational levels (junior middle school and below, senior high school, and university and above) revealed that a higher education level of parents was associated with a higher app usage $(4 / 64,6.3 \%$ vs $6 / 41,14.6 \%$ vs $17 / 65$, $26.2 \% ; P=.008)$. App usage in children was higher than that in adolescents, but the difference was not statistically significant $(21 / 106,19.8 \%$ vs $7 / 72,9.7 \% ; P=.07)$.

A univariate regression analysis showed that app use by adult patients was significantly associated with age, annual family income, occupation, education, locus, type of diabetes, and 
treatment $(P<.05)$. Gender, disease duration, and rural or urban residence had no correlation with app use. Variables with statistical significance were included in the multivariate regression analysis. Diabetes type, age, education, annual family income, and location remained statistically significant $(P<.05)$. Compared with low-income patients, patients with high income had higher app usage $(\mathrm{OR}=1.73,95 \%$ CI 1.07-2.81; $P=.03)$. The use of apps decreased with patient age. Notably, the higher the education level of the patients, the higher was the usage of apps (see Table 2).

\section{Patients' Need for and Selection of Diabetes Apps}

Patients with both T1DM and T2DM believed that the most important functions of a diabetes app were diabetes diaries (blood sugar, diet, exercise, and medication records) and doctor-patient communication (Table 3). Patients with T2DM had a greater demand for doctor-patient communication (299/733, $40.8 \%$ vs $151 / 473,31.9 \% ; P=.002)$, and patients with T1DM had a greater demand for an insulin dose calculator $(51 / 473,10.8 \%$ vs $11 / 733,1.5 \% ; P<.001)$. Almost all patients believed that the listed functions were important or very important (Figure 2).

Table 2. Factors associated with app use by multivariate logistic regression analysis ( $\mathrm{N}=1008)$.

\begin{tabular}{|c|c|c|c|}
\hline Characteristics & App usage rate, $\mathrm{n}(\%)$ & Adjusted odds ratio $(95 \% \mathrm{CI})$ & $P$ value \\
\hline \multicolumn{4}{|l|}{ Age (years) } \\
\hline $18-39^{\mathrm{a}}$ & $97(27.2)$ & $-\mathrm{b}$ & - \\
\hline $40-59$ & $47(10.7)$ & $0.42(0.27-0.65)$ & $<.001$ \\
\hline$\geq 60$ & $19(9.0)$ & $0.40(0.22-0.72)$ & .002 \\
\hline \multicolumn{4}{|l|}{ Annual family income ${ }^{c}$} \\
\hline$¥<50,000^{\mathrm{a}}$ & $34(10.9)$ & - & - \\
\hline$¥ 50,000-100,000$ & $50(16.1)$ & $1.38(0.84-2.28)$ & .20 \\
\hline$¥>100,000$ & $79(20.5)$ & $1.73(1.07-2.81)$ & .03 \\
\hline \multicolumn{4}{|l|}{ Diabetes type } \\
\hline $\mathrm{T} 2 \mathrm{DM}^{\mathrm{a}, \mathrm{d}}$ & $78(11.2)$ & - & - \\
\hline $\mathrm{T}_{1 \mathrm{DM}}^{\mathrm{e}}$ & $76(29.7)$ & $2.0(1.30-3.05)$ & .001 \\
\hline Gestational diabetes & $3(11.1)$ & $0.47(0.13-1.67)$ & .25 \\
\hline Unknown type & $6(16.2)$ & $0.15(0.45-2.93)$ & .77 \\
\hline \multicolumn{4}{|l|}{ Location } \\
\hline The other 20 provinces $^{\mathrm{a}}$ & $96(14.1)$ & - & - \\
\hline 10 provinces of the top GDP ${ }^{f}$ per capita & $67(20.5)$ & $1.5(1.04-2.17)$ & .03 \\
\hline \multicolumn{4}{|l|}{ Education } \\
\hline Junior middle school or below ${ }^{\mathrm{a}}$ & $18(7.6)$ & - & - \\
\hline High school & $49(15.0)$ & $1.85(1.02-3.37)$ & .04 \\
\hline University or above & $96(21.7)$ & $2.40(1.34-4.25)$ & .003 \\
\hline
\end{tabular}

${ }^{\mathrm{a}}$ Reference group.

${ }^{\mathrm{b}}$ Not applicable.

${ }^{c} 90$ samples with missing data on family income were excluded from the logistic regression analysis.

${ }^{\mathrm{d}}$ T2DM: type 2 diabetes mellitus.

T1DM: type 1 diabetes mellitus.

${ }^{\mathrm{f}} \mathrm{GDP}$ : gross domestic product. 
Table 3. App functions considered to be most important by patients with both T1DM and T2DM.

\begin{tabular}{llll}
\hline Features & $\mathrm{T}_{\mathrm{DM}}^{\mathrm{a}}(\mathrm{N}=473), \mathrm{n}(\%)$ & $\frac{\mathrm{T}_{2} \mathrm{DM}^{\mathrm{b}}(\mathrm{N}=733), \mathrm{n}(\%)}{P \text { value }}$ \\
\hline Diabetes diaries & $109(23.0)$ & $192(26.2)$ & .22 \\
Doctor-patient communication & $151(31.9)$ & $299(40.8)$ & .002 \\
Diabetes education knowledge & $54(11.2)$ & $86(11.7)$ & .87 \\
Peer support & $13(2.7)$ & $10(1.4)$ & .09 \\
Insulin dose calculator & $51(10.8)$ & $11(1.5)$ & .001 \\
Abnormal blood sugar reminder & $60(12.7)$ & $85(11.6)$ & .57 \\
Blood sugar test reminder & $8(1.7)$ & $15(2.0)$ & .66 \\
Others & $27(5.7)$ & $35(4.8)$ & .47 \\
\hline
\end{tabular}

aT1DM: type 1 diabetes mellitus.

${ }^{\mathrm{b}} \mathrm{T} 2 \mathrm{DM}$ : type 2 diabetes mellitus.

${ }^{\mathrm{c}}$ A Chi-square test was used to calculate $P$ values.

Figure 2. Importance of different app functions reported by patients with diabetes $(\mathrm{N}=1276)$.

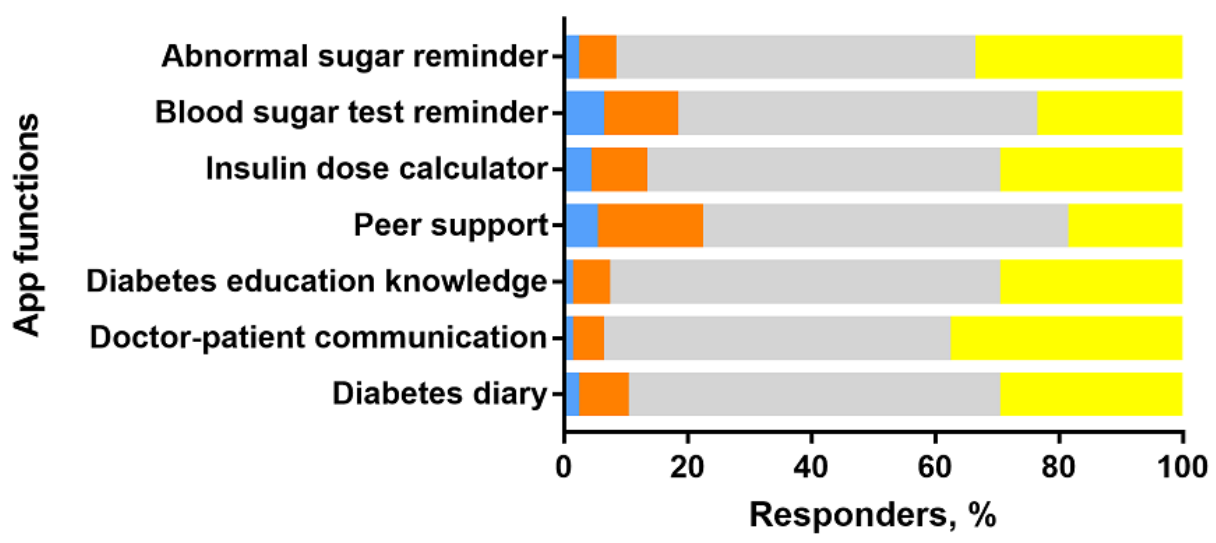

Not important at all

A little important Important Very important
Differences in app selection were found between patients with T1DM and patients with T2DM (see Table 4). The most popular app among patients with T1DM was Diabetes Circle (30/108, $27.8 \%$ ), which is targeted for patients with T1DM, followed by Diabetes Nurse $(28 / 108,25.9 \%)$ to which blood sugar tested by a Dnurse glucometer (Sinocare Inc) can be directly transmitted. The most popular app among patients with T2DM was Diabetes Nurse $(34 / 79,43.0 \%)$.
Only 19.3\% (38/197) of the apps were recommended by HCPs. Most patients selected diabetes apps as recommended by other patients $(55 / 197,27.9 \%)$ or selected randomly because they did not know which one was best $(54 / 197,27.4 \%)$. The rest were recommended by the media $(30 / 197,15.2 \%)$ or other channels $(20 / 197,10.2 \%)$.

Table 4. Differences in the selection of diabetes apps between patients with type 1 diabetes mellitus (T1DM) and patients with type 2 diabetes mellitus (T2DM).

\begin{tabular}{llll}
\hline App name & T1DM (N=108), n (\%) & T2DM (N=79), n (\%) & $P$ value \\
\hline Welltang (Shanghai Geping Information Technology Co, Ltd) & $24(22.2)$ & $5(6.3)$ & .003 \\
Diabetes Circle (Aibaowei Biotechnology Co, Ltd) & $30(27.8)$ & $3(3.8)$ & $<.001$ \\
Control Diabetes (Fuzhou Kangwei Network Technology Co, Ltd) & $1(0.9)$ & $5(6.3)$ & .08 \\
Diabetes Doctor (Shanghai Huima Medical Technology Co, Ltd) & $6(5.6)$ & $14(17.7)$ & .008 \\
Diabetes Nurse (Beijing Dnurse Technology Co,Ltd) & $28(25.9)$ & $34(43.0)$ & .01 \\
Others & $19(17.6)$ & $18(22.8)$ & .38 \\
\hline
\end{tabular}

${ }^{\mathrm{a}} \mathrm{A}$ Chi-square test was used to calculate the $P$ values. 


\section{Patients' Perspectives on Diabetes Apps}

Among the patients who had used diabetes apps, the reasons for discontinuation of use included limited time (59/197, 29.9\%), complicated operations $(50 / 197,25.4 \%)$, ineffectiveness for glycemic control $(48 / 197,24.4 \%)$, cost $(38 / 197,19.3 \%)$, and others $(48 / 197,24.4 \%)$. Most patients thought that the diabetes app was very helpful $(89 / 197,45.2 \%)$ or helpful $(67 / 197,34.0 \%)$ to them. Overall, $14.2 \%(28 / 197)$ of the patients thought it was a little helpful. Only $6.6 \%(13 / 197)$ of them thought it was unhelpful.

Of the patients, $58.4 \%(115 / 197)$ indicated that their apps had a function for consulting HCPs and, of these patients, $50.4 \%$ (58/115) had used the function to consult an HCP. The proportion of patients with T2DM who consulted HCPs was higher than that of patients with T1DM, but this difference was not statistically significant $(26 / 46,57 \%$ vs $28 / 61,46 \% ; P=.28)$. A total of $67 \%(39 / 58)$ of their consultations were free. Most patients thought that these consultations were helpful $(33 / 58$, $57 \%)$ or very helpful $(4 / 58,7 \%)$. The reasons cited by the patients as affecting the effectiveness of the consultation included short consultation time $(25 / 58,43 \%)$, delayed response
(15/58, 26\%), unqualified HCPs $(10 / 58,17 \%)$, and others $(8 / 58$, $14 \%)$.

\section{Patients'Attitudes Toward Diabetes Apps}

Only $34.87 \%$ (445/1276) of patients believed that consulting HCPs via apps should cost money. However, 59.72\% (762/1276) of these indicated that they would continue to use this function if the consultation effect was good. Of these, $8.30 \%(106 / 1276)$ said they would certainly continue to use and $31.97 \%$ (408/1276) said they would not continue to use the app if they had to pay. Almost all patients said they were in need (889/1276, 69.67\%) or in great need $(335 / 1276,26.25 \%)$ of a good app to help with their glycemic control. Only $4.08 \%$ (52/1276) of them said they did not need a diabetes app.

\section{Diabetologist Survey}

\section{Diabetologists' Recommendation and Use of Diabetes Management Apps and Associated Factors}

In total, 608 diabetologists (223 from North China and 385 from South China) from 21 provinces in China responded to the diabetologist survey. Table 5 shows the characteristics of the surveyed diabetologists.

Table 5. Characteristics of the surveyed diabetologists $(\mathrm{N}=608)$.

\begin{tabular}{ll}
\hline Characteristics & Statistics \\
\hline Gender, $\mathbf{n}(\boldsymbol{\%})$ & $197(32.4)$ \\
$\quad$ Male & $411(67.6)$ \\
$\quad$ Female & \\
Age (years), $\mathbf{n}(\boldsymbol{\%})$ & $99(16.3)$ \\
$\leq 30$ & $274(45.1)$ \\
$30-39$ & $162(26.6)$ \\
$40-49$ & $67(11.0)$ \\
$50-59$ & $6(1.0)$ \\
$\geq 60$ & $141(23.2)$ \\
Title, $\mathbf{n}(\boldsymbol{\%})$ & $239(39.3)$ \\
Resident & $125(20.6)$ \\
Attending specialist & $103(16.9)$ \\
Associate chief doctor & \\
Chief doctor & $419(68.9)$ \\
Hospital level, $\mathbf{n}(\boldsymbol{\%})$ & $189(31.0)$ \\
Tertiary hospital & \\
Secondary hospital or lower & \\
\hline
\end{tabular}


Figure 3. App awareness rate, recommendation rate, and usage among different age groups of diabetologists $(\mathrm{N}=608)$.

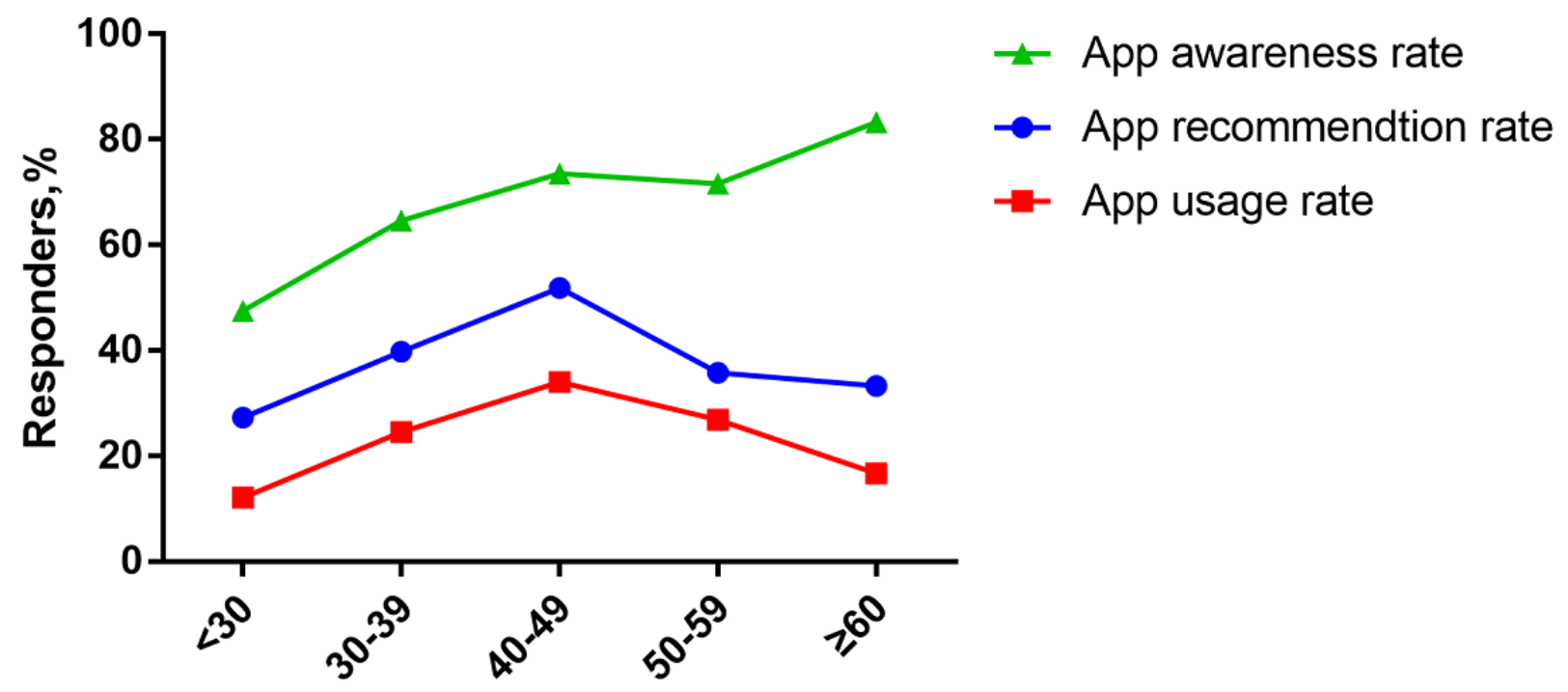

Age groups

Of the diabetologists, $43.8 \%$ (266/608) had downloaded a diabetes management app, $40.5 \%(246 / 608)$ of them had recommended diabetes apps to their patients, and $25.2 \%$ (153/608) used diabetes apps to manage their patients. The app awareness rate was lowest in the doctor group younger than 30 years $(47 / 99,47 \%)$ and it gradually increased with age $(P<.001)$. App recommendation rate and usage increased gradually with the age of doctors. The highest recommendation rate and usage were found in the 40 to 49 age group (84/162, 51.9\% and $55 / 162,34.0 \%$, respectively), and then decreased again with age $(P=.002$ and $P=.003$, respectively; Figure 3$)$. The app recommendation rate and usage among doctors in tertiary hospitals were higher than those in secondary or lower hospitals $(190 / 419,45.3 \%$ vs $56 / 189,29.6 \% ; P<.001$ and $119 / 419,28.4 \%$ vs $34 / 189,18 \% ; P<.001)$.

The app most recommended by diabetologists was Diabetes Doctor $(56 / 246,22.8 \%)$, which enables doctors to follow their patients, followed by Welltang $(45 / 246,18.3 \%)$, which is the only app tested via an RCT in China. The most important factors that influenced diabetologists' recommendations of apps to their patients included not knowing of a suitable app (296/608, $48.7 \%)$, not knowing of the existence of diabetes apps (212/608, $34.9 \%)$, no time to recommend $(182 / 608,29.9 \%)$, no evidence demonstrating their effectiveness $(90 / 608,14.8 \%)$, no effect on blood sugar $(47 / 608,7.7 \%)$, and others $(49 / 608,8.1 \%)$.

The greatest obstacles to diabetologists' use of apps to manage patients with diabetes include limited time $(280 / 608,46.1 \%)$, legal issues $(129 / 608,21.2 \%)$, patients' distrust (108/608, $17.8 \%)$, uncertainty on how to bill patients $(66 / 608,10.9 \%)$, and others $(25 / 608,4.1 \%)$. The proportion of diabetologists in tertiary hospitals who thought the largest obstacle was limited time was higher than that in secondary or lower hospitals
(212/419, 50.6\% vs $68 / 189,36.0 \% ; P=.001)$. The proportion of doctors who believed that the greatest obstacle was patient distrust was higher in doctors from secondary or lower hospitals and junior doctors than in doctors from tertiary hospitals and among senior doctors $(47 / 189,24.9 \%$ vs $61 / 419,14.6 \% ; P=.002$; and $38 / 141,27.0 \%$ vs $70 / 467,15.0 \% ; P=.001$, respectively).

In all, 94\% (141/150) of the diabetologists use apps to manage patients free of charge. Most of them managed less than 50 patients $(125 / 150,83.3 \%)$. Most diabetologists who had managed patients with an app thought that the app had some effect $(83 / 150,55.3 \%)$ or minimal effect $(58 / 150,38.7 \%)$ on blood sugar, whereas $2.0 \%(3 / 150)$ thought it had no effect and $4 \%(6 / 150)$ thought it was very effective. Most diabetologists did not know whether it was legal to use apps to manage patients $(311 / 608,51.2 \%)$, and $33.6 \%(204 / 608)$ and $15.3 \%(93 / 608)$ thought that using an app for this purpose was legal and illegal, respectively.

\section{Diabetologists' Perspectives of Diabetes Apps}

The diabetologists believed that the most important functions of a diabetes app were diabetes diaries $(247 / 608,40.6 \%)$ and doctor-patient communication (233/608, 38.4\%; Figure 4). Of the diabetologists, $71.5 \%$ (435/608) believed that patients with T1DM and patients with T2DM needed different apps.

Diabetologists believed that the reasons for the poor effect of a diabetes app on blood sugar included the following: patients could not adhere to the use of apps (431/608, 70.9\%); HCPs did not participate in apps or gave too little guidance for patients $(383 / 608,63 \%)$, diabetes education knowledge on an app was not systematic $(280 / 608,46.1 \%)$, apps lacked comprehensive functions $(225 / 608,37.0 \%)$, and others $(16 / 608,2.6 \%)$. 
Figure 4. Diabetes app functions considered to be most important by diabetologists (N=608).

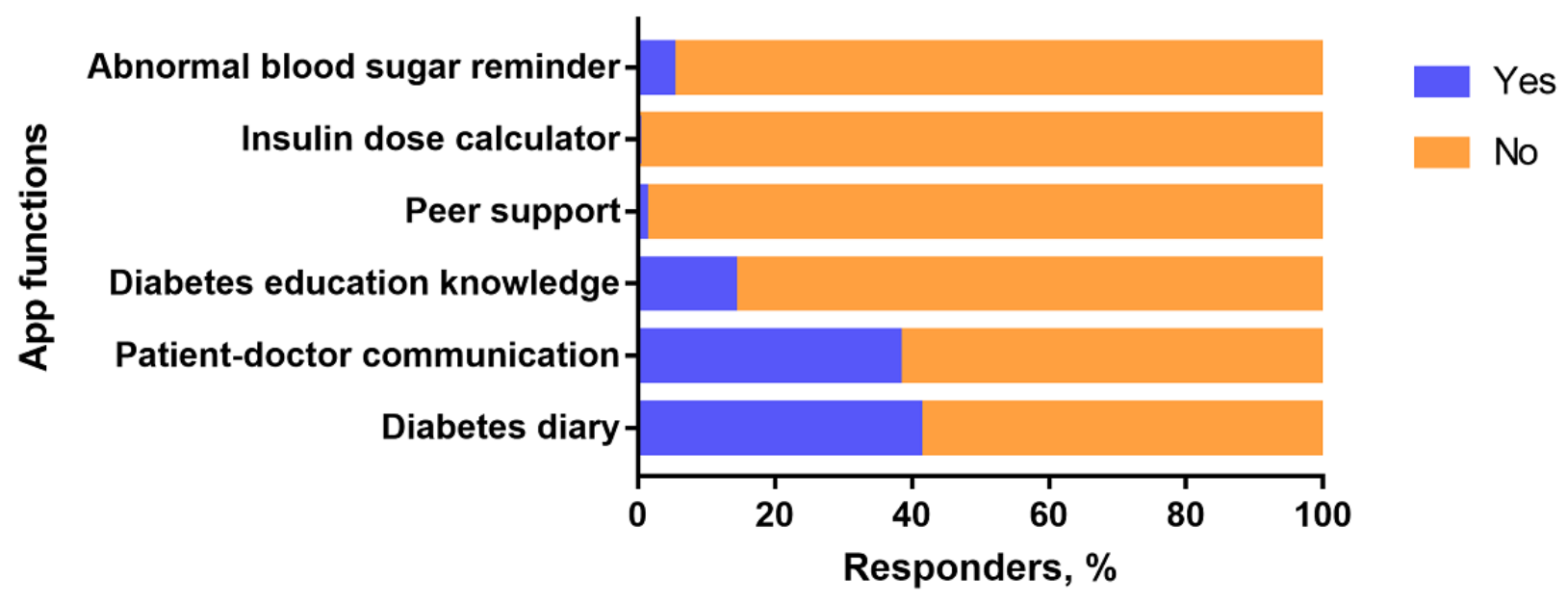

\section{Diabetologists'Attitudes Toward Diabetes Apps}

Most diabetologists said they might (380/608, 62.5\%) or would certainly $(219 / 608,36 \%)$ use a diabetes app to manage patients in the future. Only $1.5 \%(9 / 608)$ indicated that they would not manage diabetes patients using an app. Most said that they might $(349 / 608,57.4 \%)$ or would definitely $(253 / 608,41.6 \%)$ recommend diabetes apps to their patients, whereas only $1.0 \%$ $(6 / 608)$ said that they would not recommend one. Most diabetologists believed that diabetes apps showed good $(325 / 608,53.5 \%)$ or very good $(127 / 608,20.9 \%)$ potential.

\section{Discussion}

\section{Principal Findings}

\section{Diabetes App Use among Diabetes Patients and Its Associated Factors}

App usage was $22.8 \%$ among patients with T1DM and $10.8 \%$ among patients with T2DM, which was comparable with surveys conducted in New Zealand [22] and Australia [23], and higher than the 7\% found in a Scottish survey in 2016 [25] and the 3\% found among Latinos in 2015 [21]. The app usage of patients with T2DM in China was lower than that of patients with T1DM and was associated with age, education, family income, and location. The possible reasons are that younger patients and well-educated patients are more likely to acquire and accept new technology, and those with higher household income are more likely to focus on their glycemic control and actively seek new ways to control blood sugar. China's economic development is unbalanced, and medical resources are unevenly distributed and relatively concentrated in economically developed areas [7]. There are obvious regional differences in glycemic control in China [39]. The regional difference in app usage might be related to these differences in glycemic control. Furthermore, the app usage among patients with T2DM was lower than that among patients with T1DM, which is consistent with former studies $[22,23]$. This finding may be because the blood sugar of patients with T1DM is more difficult to control and their need for an app is greater.
We found that the app usage in children was higher than that in adolescents, possibly because children's blood sugar is always managed by their parents, as their parents use diabetes apps to help with glycemic control. However, adolescents gradually withdraw support from their parents and take over the management tasks.

\section{Suggestions for Promoting Diabetes App Use}

App use among patients with diabetes in China is low, largely because of the low awareness of diabetes apps. Only $29.94 \%$ of the patients knew that diabetes apps existed, but only half of these patients who knew of diabetes apps would use one. Additionally, many doctors, particularly younger doctors, had no information on diabetes apps. Specifically, younger doctors had less awareness of diabetes apps than did senior doctors, which might be related to younger doctors having less awareness of the progress made in diabetes treatment. Therefore, public awareness of diabetes apps must be increased.

Our study found that only a small number of patient apps were recommended by doctors. Most apps were recommended by patients or were casually chosen. In total, $40.5 \%$ of the diabetologists in China recommended diabetes apps to their patients, which was lower than the $60.1 \%$ found in the New Zealand survey [22] and the $62 \%$ found in the US survey [40]. The most important factor that influenced diabetologists' recommendation of apps to patients was that they had no idea of a suitable one among the numerous apps. Although there are thousands of diabetes apps, only a small number of them were tested for efficacy [31]. The quality of the studies was not high, and the effects of the apps on blood sugar were inconsistent [41]. Thus, it is difficult for HCPs to recommend a suitable app to their patients. Therefore, it is very important to carry out high-quality RCTs to test app efficacy [42].

\section{Barriers to Doctor-Patient Communication and Suggestions for Improvement}

Both diabetologists and patients believed that doctor-patient communication and diabetes diaries were the most important functions of a diabetes app, which was consistent with our previous report [26]. The app most recommended by 
diabetologists was one that doctors could use to follow-up with their patients. However, only $25.2 \%$ of the diabetologists managed diabetes patients with apps.

The main reasons given by diabetologists as affecting patient management with apps were limited time, issue of legality, and patients' distrust. More doctors in tertiary hospitals than in primary hospitals thought that the largest obstacle to using an app to manage patients with diabetes was limited time, and more younger doctors and doctors from primary hospitals believed that patients' distrust was the largest obstacle. Therefore, improving the specialty of young doctors and doctors from primary hospitals can effectively improve patients' trust in these doctors, reduce the burden on senior doctors from tertiary hospitals, and effectively promote using diabetes apps to manage patients. Fortunately, the Chinese government is actively promoting standardized training for residents and a hierarchical medical system, which will effectively reduce the burden on doctors from tertiary hospitals, improve the specialties of young doctors and doctors from primary hospitals, and enhance patients' trust in them. Owing to a lack of face-to-face physical examinations and complete medical histories, most doctors did not know whether using an app to manage patients was legal. China is vigorously promoting internet health care and improving relevant legislations [43]. Therefore, it may become possible for doctors to manage their patients with an app.

The approach used to bill patients was also a reason given by diabetologists that affected patient management. At present, most diabetologists use apps to manage patients free of charge, which affects the HCP's enthusiasm. Medical insurance should be included, and an effective billing system should be established.

\section{Suggestions for the Design of Diabetes Apps}

There were a few differences in the needs of an app between patients with T1DM and patients with T2DM. More patients with T1DM believed that the insulin dose calculator was the most important function of diabetes apps. Patients with T1DM rely on insulin therapy, and insulin dosage must be adjusted according to diet and exercise. Thus, these patients have a greater need for this function. There were also differences in the choice of apps between the 2 groups. The most common choice of patients with T1DM was an app targeted for patients with T1DM (Diabetes Circle). The most common choice of patients with T2DM was Diabetes Nurse, to which blood sugar tested by a Dnurse glucometer can be directly transmitted. Additionally, most doctors believed that patients with T1DM and patients with T2DM need different apps. Therefore, apps should be designed according to different types of diabetes patients' demands.

The data entry burden is the major reason why patients cannot persist in using an app [44]. Data transferred directly from a glucometer to an app will reduce the data entry burden, which is why most patients chose the Diabetes Nurse app. Diabetologists believed that the main reason why an app was ineffective was that patients could not persist in using it. The main reasons why patients did not want to continue to use an app were lack of time and complicated operations. Therefore, app design should enable blood sugar data from glucometers to be automatically transmitted to the app, which will greatly increase patient compliance.

Of the diabetologists, $46.1 \%$ believed that a lack of systematic and standardized diabetes education knowledge was a reason for the poor efficacy of apps. Most apps do not have educational information cited from accredited sources [45]. Previous studies indicated that a mobile app was preferable to receiving DSMES in a hospital $[26,46]$. Therefore, diabetes education knowledge compiled by a multidisciplinary team will effectively improve patients' self-management ability and improve the effectiveness of an app.

\section{Prospect of Diabetes Apps}

Almost all patients indicated that they needed an effective app to manage blood sugar. Almost all diabetologists said they would or could use diabetes apps to manage patients and recommend diabetes apps to their patients. China has the largest number of patients with diabetes in the world [2], and our results suggest that diabetes apps have a very good future in China.

\section{Comparison With Prior Work}

To our knowledge, no large-scale investigations have been conducted on diabetes app use among people with diabetes in China. An Australian survey suggested that disease duration was related to the use of app in diabetes patients [23,24]. Our study did not find such an association, probably because of different samples. The Australian survey only investigated patients with a disease duration of more than 1 year, and our study included patients of all disease durations. Furthermore, the disease durations were self-reported and might be inaccurate. Our study found that diabetes app users tended to be younger, have higher incomes, and be more educated, which was consistent with a health app survey in the United States [44].

Boyle et al investigated both diabetes patients and HCPs for their use and beliefs about diabetes apps. They also found that diabetes diaries were most useful for diabetes patients [22]. Our strength was that we recruited a large sample throughout China, and we also investigated the patient-doctor communication feature from the perspectives of both patients and doctors, which is considered to be the most important function by both patients and diabetologists [26].

Few studies have surveyed diabetes app use from the point of view of HCPs. Karduck and Chapman-Novakofski investigated clinicians' perspectives on mHealth apps and found that most clinicians (62\%) recommended mobile phone apps to their patients to track their diet and physical activity [40]. Our study found a $40.5 \%$ recommendation rate. However, most of their samples were nutritionists and diabetes educators. We recruited only diabetologists because diabetes patients in China are mostly treated by these doctors.

In addition to investigating patients' app use, we also investigated diabetologists' use, perspectives, and attitudes regarding diabetes apps, as well as patients' needs, perspectives, and attitudes regarding diabetes apps. Therefore, we can provide more effective information for app design and promotion of app usage and better understand the diabetes app market in China. 


\section{Limitations}

A strength of our study was that the patient and diabetologist survey links were initially sent to doctors from 46 LADA China Study collaborative hospitals in 25 representative major cities and spread on their WeChat contact networks. In addition to this snowball sampling method, patients with diabetes were surveyed via convenience sampling on 3 WeChat public accounts. Finally, our sample came from 30 provinces across China. Our research also had several limitations. First, the 1276 sampled patients did not sufficiently represent the large population of patients with diabetes in China. Second, our sampling was not stratified by geographic region, urban or rural location, socioeconomic status, age, or diabetes type. Some selection bias was unavoidable. Although the mean age of our patient sample was comparable with that of the national survey concerning diabetes prevalence in China [47], the proportion of patients with T1DM in our sample was higher than the actual disease proportion of total patients with diabetes [48]. Finally, our sampling was based on the WeChat network. Although WeChat has 1.04 billion monthly active users [49], some people do not use WeChat or surf the internet. Thus, actual app usage might be lower, particularly among elderly patients.

Our study was a cross-sectional survey. Although patients' perspectives and attitudes are very important when developing a mobile app for their use [50,51], people's attitudes toward what is useful and what might work are heavily anchored in their present experience regarding the development of technology and how it is implemented. Therefore, these findings must be updated over time as technology develops and people's perceptions change. Furthermore, many factors influence app use. Although we adjusted for some factors in the multivariate analysis, other potential confounding factors remain.

\section{Conclusions}

Using an exploratory approach, we found that awareness and use of diabetes apps among the Chinese diabetic population and the proportion of diabetologists using diabetes apps to manage patients are low. There are a few differences in the needs for and choice of diabetes apps between patients with T1DM and patients with T2DM. Therefore, designing apps targeted for different patients' needs and conducting high-quality RCTs will improve the effectiveness of apps, provide evidence for patients to choose suitable apps, and be conducive to the promotion of diabetes apps. China should increase public awareness of diabetes apps, and relevant policies and regulations are needed to support doctors' use of apps to manage patients. Diabetes app use in China has good potential. Diabetes apps are potentially effective supplements that can be used in traditional outpatient clinics to improve glycemic control in Chinese patients with diabetes.

\section{Acknowledgments}

The authors thank all the participants for sharing their perspectives in the course of this study. The authors also thank American Journal Experts for their assistance in language editing.

This work was supported by the National Key R\&D Program of China (2017YFC1309604), (2018YFC1315603) and the Natural Science Foundation of Hunan Province, China (2018JJ2573).

\section{Conflicts of Interest}

None declared.

\section{References}

1. Cho NH, Shaw JE, Karuranga S, Huang Y, da Rocha JD, Ohlrogge AW, et al. IDF Diabetes Atlas: global estimates of diabetes prevalence for 2017 and projections for 2045. Diabetes Res Clin Pract 2018 Apr;138:271-281. [doi: 10.1016/j.diabres.2018.02.023] [Medline: 29496507]

2. Xu Y, Wang L, He J, Bi Y, Li M, Wang T, 2010 China Noncommunicable Disease Surveillance Group. Prevalence and control of diabetes in Chinese adults. J Am Med Assoc 2013 Sep 4;310(9):948-959. [doi: 10.1001/jama.2013.168118] [Medline: 24002281]

3. Nathan DM. Long-term complications of diabetes mellitus. N Engl J Med 1993 Jun 10;328(23):1676-1685. [doi: 10.1056/NEJM199306103282306] [Medline: $\underline{\text { 8487827] }}$

4. Bommer C, Heesemann E, Sagalova V, Manne-Goehler J, Atun R, Bärnighausen T, et al. The global economic burden of diabetes in adults aged 20-79 years: a cost-of-illness study. Lancet Diabetes Endocrinol 2017 Dec;5(6):423-430. [doi: 10.1016/S2213-8587(17)30097-9] [Medline: 28456416]

5. Beck J, Greenwood DA, Blanton L, Bollinger ST, Butcher MK, Condon JE, 2017 Standards Revision Task Force. 2017 National Standards for Diabetes Self-Management Education and Support. Diabetes Care 2017 Dec;40(10):1409-1419. [doi: $10.2337 /$ dci17-0025] [Medline: 28754780]

6. American Diabetes Association. 6. Glycemic targets: Standards of Medical Care in Diabetes-2018. Diabetes Care 2018 Dec;41(Suppl 1):S55-S64. [doi: 10.2337/dc18-S006] [Medline: 29222377]

7. Chen Y, Yin Z, Xie Q. Suggestions to ameliorate the inequity in urban/rural allocation of healthcare resources in China. Int J Equity Health 2014;13:34 [FREE Full text] [doi: 10.1186/1475-9276-13-34] [Medline: 24884614]

8. Li Q, Xie P. Outpatient workload in China. Lancet 2013 Jun 8;381(9882):1983-1984. [doi: 10.1016/S0140-6736(13)61198-8] [Medline: 23746895] 
9. Hu Y, Zhang Z. Skilled doctors in tertiary hospitals are already overworked in China. Lancet Glob Health 2015 Dec;3(12):e737 [FREE Full text] [doi: 10.1016/S2214-109X(15)00192-8] [Medline: 26566744]

10. Chyxx. [Analysis of development and prospect of smart phone industry in China in 2018 and its development prospects] URL: http://www.chyxx.com/industry/201803/620359.html [accessed 2018-10-22] [WebCite Cache ID 73MRoAWBg]

11. Hsu J, Liu D, Yu YM, Zhao HT, Chen ZR, Li J, et al. The top Chinese mobile health apps: a systematic investigation. J Med Internet Res 2016 Aug 29;18(8):e222 [FREE Full text] [doi: 10.2196/jmir.5955] [Medline: 27573724]

12. Kleinman NJ, Shah A, Shah S, Phatak S, Viswanathan V. Impact of the Gather mHealth system on A1C: primary results of a multisite randomized clinical trial among people with type 2 diabetes in India. Diabetes Care 2016 Dec;39(10):e169-e170. [doi: 10.2337/dc16-0869] [Medline: 27493133]

13. Zhou W, Chen M, Yuan J, Sun Y. Welltang-a smart phone-based diabetes management application - improves blood glucose control in Chinese people with diabetes. Diabetes Res Clin Pract 2016 Jun;116:105-110. [doi: 10.1016/j.diabres.2016.03.018] [Medline: 27321324]

14. Waki K, Fujita H, Uchimura Y, Omae K, Aramaki E, Kato S, et al. DialBetics: a novel smartphone-based self-management support system for type 2 diabetes patients. J Diabetes Sci Technol 2014 Mar 13;8(2):209-215 [FREE Full text] [doi: 10.1177/1932296814526495] [Medline: 24876569]

15. Garg SK, Shah VN, Akturk HK, Beatson C, Snell-Bergeon JK. Role of mobile technology to improve diabetes care in adults with type 1 diabetes: the remote-T1D Study iBGStar((R)) in type 1 diabetes managemen. Diabetes Ther 2017 Aug;8(4):811-819 [FREE Full text] [doi: 10.1007/s13300-017-0272-5] [Medline: 28555339]

16. Bonoto BC, de Araújo VE, Godói IP, de Lemos LL, Godman B, Bennie M, et al. Efficacy of mobile apps to support the care of patients with diabetes mellitus: a systematic review and meta-analysis of randomized controlled trials. JMIR Mhealth Uhealth 2017 Mar 1;5(3):e4 [FREE Full text] [doi: 10.2196/mhealth.6309] [Medline: 28249834]

17. American Diabetes Association. 4. Lifestyle management: Standards of Medical Care in Diabetes-2018. Diabetes Care 2018 Jan;41(Suppl 1):S38-S50. [doi: 10.2337/dc18-S004] [Medline: 29222375]

18. Hou C, Xu Q, Diao S, Hewitt J, Li J, Carter B. Mobile phone applications and self-management of diabetes: a systematic review with meta-analysis, meta-regression of 21 randomized trials and GRADE. Diabetes Obes Metab 2018 Dec;20(8):2009-2013. [doi: 10.1111/dom.13307] [Medline: 29582538]

19. Offringa R, Sheng T, Parks L, Clements M, Kerr D, Greenfield MS. Digital diabetes management application improves glycemic outcomes in people with type 1 and type 2 diabetes. J Diabetes Sci Technol 2018 May;12(3):701-708 [FREE Full text] [doi: 10.1177/1932296817747291] [Medline: 29277103]

20. Husted GR, Weis J, Teilmann G, Castensøe-Seidenfaden P. Exploring the influence of a smartphone app (Young with Diabetes) on young people's self-management: qualitative study. JMIR Mhealth Uhealth 2018 Feb 28;6(2):e43 [FREE Full text] [doi: 10.2196/mhealth.8876] [Medline: 29490897]

21. Williams JP, Schroeder D. Popular glucose tracking apps and use of mhealth by Latinos with diabetes: review. JMIR Mhealth Uhealth 2015;3(3):e84 [FREE Full text] [doi: 10.2196/mhealth.3986] [Medline: 26307533]

22. Boyle L, Grainger R, Hall RM, Krebs JD. Use of and beliefs about mobile phone apps for diabetes self-management: surveys of people in a hospital diabetes clinic and diabetes health professionals in New Zealand. JMIR Mhealth Uhealth 2017 Jun 30;5(6):e85 [FREE Full text] [doi: 10.2196/mhealth.7263] [Medline: 28666975]

23. Trawley S, Baptista S, Browne JL, Pouwer F, Speight J. The use of mobile applications among adults with type 1 and type 2 diabetes: results from the second MILES-Australia (MILES-2) study. Diabetes Technol Ther 2017 Dec;19(12):730-738. [doi: 10.1089/dia.2017.0235] [Medline: 29028442]

24. Trawley S, Browne JL, Hagger VL, Hendrieckx C, Holmes-Truscott E, Pouwer F, et al. The use of mobile applications among adolescents with type 1 diabetes: results from Diabetes MILES Youth-Australia. Diabetes Technol Ther 2016 Dec;18(12):813-819. [doi: 10.1089/dia.2016.0233] [Medline: 27788032]

25. Conway N, Campbell I, Forbes P, Cunningham S, Wake D. mHealth applications for diabetes: user preference and implications for app development. Health Informatics J 2016 Dec;22(4):1111-1120. [doi: 10.1177/1460458215616265] [Medline: 26635324]

26. Zhang Y, Li X, Luo S, Liu C, Liu F, Zhou Z. Exploration of users' perspectives and needs and design of a type 1 diabetes management mobile app: mixed-methods study. JMIR Mhealth Uhealth 2018 Sep 21;6(9):e11400 [FREE Full text] [doi: 10.2196/11400] [Medline: 30249580 ]

27. Chavez S, Fedele D, Guo Y, Bernier A, Smith M, Warnick J, et al. Mobile apps for the management of diabetes. Diabetes Care 2017 Oct;40(10):e145-e146. [doi: 10.2337/dc17-0853] [Medline: 28774944]

28. Wu Y, Yao X, Vespasiani G, Nicolucci A, Dong Y, Kwong J, et al. Mobile app-based interventions to support diabetes self-management: a systematic review of randomized controlled trials to identify functions associated with glycemic efficacy. JMIR Mhealth Uhealth 2017 Mar 14;5(3):e35 [FREE Full text] [doi: 10.2196/mhealth.6522] [Medline: 28292740]

29. Chomutare T, Fernandez-Luque L, Arsand E, Hartvigsen G. Features of mobile diabetes applications: review of the literature and analysis of current applications compared against evidence-based guidelines. J Med Internet Res 2011;13(3):e65 [FREE Full text] [doi: 10.2196/jmir.1874] [Medline: 21979293]

30. Nie L, Xie B, Yang Y, Shan YM. Characteristics of Chinese m-Health applications for diabetes self-management. Telemed J E Health 2016 Jul;22(7):614-619. [doi: 10.1089/tmj.2015.0184] [Medline: 27171016] 
31. Drincic A, Prahalad P, Greenwood D, Klonoff DC. Evidence-based mobile medical applications in diabetes. Endocrinol Metab Clin North Am 2016 Dec;45(4):943-965 [FREE Full text] [doi: 10.1016/j.ecl.2016.06.001] [Medline: 27823614]

32. American Diabetes Association. Standards of medical care in diabetes--2014. Diabetes Care 2014 Jan;37(Suppl 1):S14-S80. [doi: 10.2337/dc14-S014] [Medline: 24357209]

33. Wikipedia. WeChat URL: https://en.wikipedia.org/wiki/WeChat [accessed 2018-10-22] [WebCite Cache ID 73MQIKI5b]

34. Zhang X, Wen D, Liang J, Lei J. How the public uses social media WeChat to obtain health information in China: a survey study. BMC Med Inform Decis Mak 2017 Jul 5;17(Suppl 2):66 [FREE Full text] [doi: 10.1186/s12911-017-0470-0] [Medline: 28699549]

35. Statista: The Stastics Portal. Average number of contacts of WeChat users in China as of 2016 URL: https://www.statista.com/ statistics/387665/wechat-china-contact-list-size/ [accessed 2018-10-22] [WebCite Cache ID 73MPvY2mm]

36. [Changsha Haoxing Information Technology Co]. [More than a questionnaire/online exam] URL: https://www.wjx.cn/ [accessed 2018-12-05] [WebCite Cache ID 74QZMJNBa]

37. Zhou Z, Xiang Y, Ji L, Jia W, Ning G, Huang G, LADA China Study Group. Frequency, immunogenetics, and clinical characteristics of latent autoimmune diabetes in China (LADA China study): a nationwide, multicenter, clinic-based cross-sectional study. Diabetes 2013 Feb;62(2):543-550 [FREE Full text] [doi: 10.2337/db12-0207] [Medline: 23086039]

38. Chyxx. [Analysis of China's per capita GDP ranking and China's per capita GDP ranking in the world in 2016] URL: https:/ /www.chyxx.com/industry/201712/591596.html [accessed 2018-10-22] [WebCite Cache ID 73MPYR6gt]

39. McGuire HC, Ji L, Kissimova-Skarbek K, Whiting D, Aguirre F, Zhang P, et al. Type 1 diabetes mellitus care and education in China: the 3C study of coverage, cost, and care in Beijing and Shantou. Diabetes Res Clin Pract 2017 Jul;129:32-42. [doi: 10.1016/j.diabres.2017.02.027] [Medline: 28500868]

40. Karduck J, Chapman-Novakofski K. Results of the Clinician Apps Survey, how clinicians working with patients with diabetes and obesity use mobile health apps. J Nutr Educ Behav 2018 Jan;50(1):62-69.e1. [doi: 10.1016/j.jneb.2017.06.004] [Medline: 29325664]

41. Istepanian RS. Mobile applications for diabetes management: efficacy issues and regulatory challenges. Lancet Diabetes Endocrinol 2015 Dec;3(12):921-923. [doi: 10.1016/S2213-8587(15)00414-3] [Medline: 26545304]

42. Holmen H, Wahl AK, Cvancarova SM, Ribu L. Tailored communication within mobile apps for diabetes self-management: a systematic review. J Med Internet Res 2017 Jun 23;19(6):e227 [FREE Full text] [doi: 10.2196/jmir.7045] [Medline: 28645890]

43. [National Health and Wellness Commission]. [Notice on Printing and Distributing 3 Documents Such as the Internet Management and Management Measures (Trial)] URL: http://www.nhfpc.gov.cn/yzygj/s3594q/201809/ c6c9dab0b00c4902a5e0561bbf0581f1.shtml [accessed 2018-10-22] [WebCite Cache ID 73MT7S8am]

44. Krebs P, Duncan DT. Health app use among US mobile phone owners: a national survey. JMIR Mhealth Uhealth 2015;3(4):e101 [FREE Full text] [doi: 10.2196/mhealth.4924] [Medline: 26537656]

45. Huang Z, Soljak M, Boehm BO, Car J. Clinical relevance of smartphone apps for diabetes management: a global overview. Diabetes Metab Res Rev 2018 May;34(4):e2990. [doi: 10.1002/dmrr.2990] [Medline: 29431916]

46. Pal K, Dack C, Ross J, Michie S, May C, Stevenson F, et al. Digital health interventions for adults with type 2 diabetes: qualitative study of patient perspectives on diabetes self-management education and support. J Med Internet Res 2018 Jan 29;20(2):e40 [FREE Full text] [doi: 10.2196/jmir.8439] [Medline: 29463488]

47. Wang L, Gao P, Zhang M, Huang Z, Zhang D, Deng Q, et al. Prevalence and ethnic pattern of diabetes and prediabetes in China in 2013. J Am Med Soc 2017 Dec 27;317(24):2515-2523. [doi: 10.1001/jama.2017.7596] [Medline: 28655017]

48. Bullard KM, Cowie CC, Lessem SE, Saydah SH, Menke A, Geiss LS, et al. Prevalence of diagnosed diabetes in adults by diabetes type - United States, 2016. MMWR Morb Mortal Wkly Rep 2018 Mar 30;67(12):359-361 [FREE Full text] [doi: 10.15585/mmwr.mm6712a2] [Medline: 29596402]

49. Statista: The Stastics Portal. Number of monthly active WeChat users from 2nd quarter 2010 to 1 st quarter 2018 (in millions) URL: https://www.statista.com/statistics/255778/number-of-active-wechat-messenger-accounts/ [accessed 2018-10-22] [WebCite Cache ID 73MS4A7Hx]

50. Pulman A, Taylor J, Galvin K, Masding M. Ideas and enhancements related to mobile applications to support type 1 diabetes. JMIR Mhealth Uhealth 2013;1(2):e12 [FREE Full text] [doi: 10.2196/mhealth.2567] [Medline: 25100684]

51. Peng W, Yuan S, Holtz BE. Exploring the challenges and opportunities of health mobile apps for individuals with type 2 diabetes living in rural communities. Telemed J E Health 2016 Sep;22(9):733-738. [doi: 10.1089/tmj.2015.0180] [Medline: 26982017]

\section{Abbreviations}

DSMES: diabetes self-management education and support

GDP: gross domestic product

$\mathbf{H b A}_{\mathbf{1 c}}$ : glycosylated hemoglobin

HCP: health care professional

IQR: interquartile range 
LADA: Latent Autoimmune Diabetes of Adults

mHealth: mobile health

OR: odds ratio

RCT: randomized controlled trial

T1DM: type 1 diabetes mellitus

T2DM: type 2 diabetes mellitus

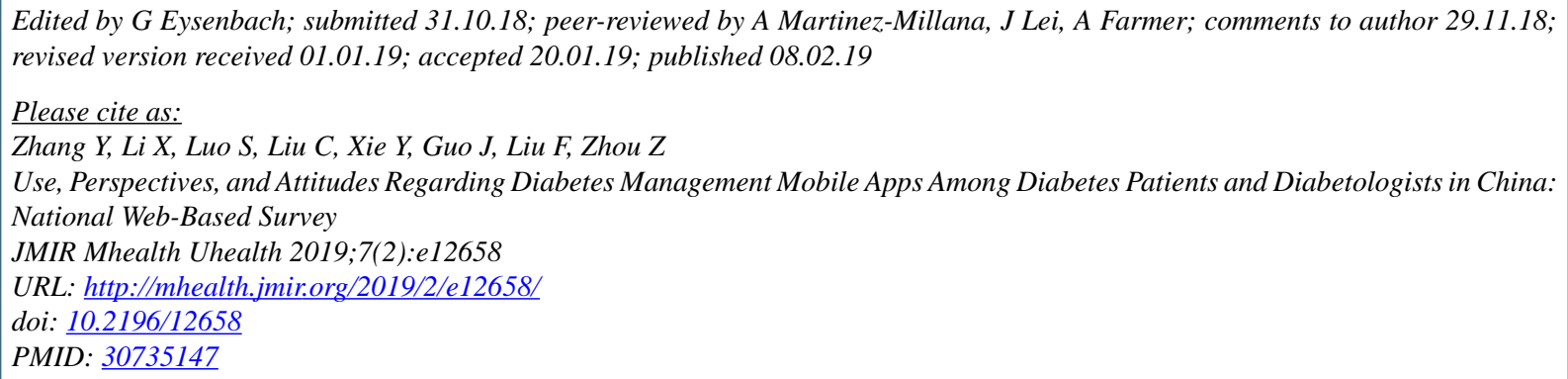

(C) Yiyu Zhang, Xia Li, Shuoming Luo, Chaoyuan Liu, Yuting Xie, Jia Guo, Fang Liu, Zhiguang Zhou. Originally published in JMIR Mhealth and Uhealth (http://mhealth.jmir.org), 08.02.2019. This is an open-access article distributed under the terms of the Creative Commons Attribution License (https://creativecommons.org/licenses/by/4.0/), which permits unrestricted use, distribution, and reproduction in any medium, provided the original work, first published in JMIR mhealth and uhealth, is properly cited. The complete bibliographic information, a link to the original publication on http://mhealth.jmir.org/, as well as this copyright and license information must be included. 